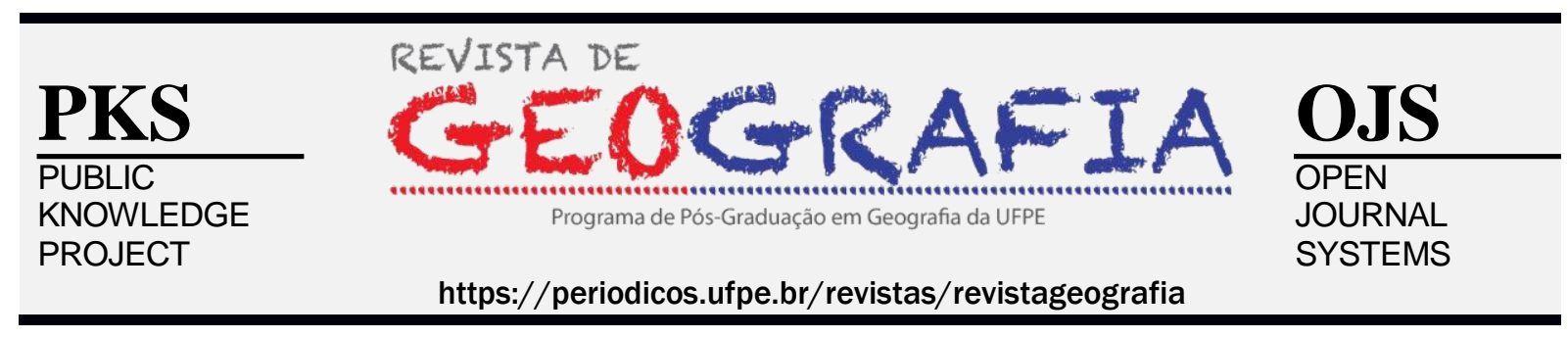

\title{
FRAGILIDADE AMBIENTAL FRENTE AO USO DO SOLO NO ALTO CAMAQUÃ, RS
}

\author{
Cibelle Machado Carvalho ${ }^{1}$, Ewerthon Schiavo Bernardi ${ }^{2}$, Roberta Aparecida Fantinel ${ }^{3}$, \\ Tiago Feldkircher ${ }^{2}$, Rafael Cabral Cruz ${ }^{4}$

\begin{abstract}
${ }^{1}$ Doutora em Engenharia Civil - Universidade Federal de Santa Maria. E-mail: cibelle_mc@yahoo.com.br ${ }^{2}$ Mestre em Engenharia Ambiental - Universidade Federal de Santa Maria. E-mail: bernardi.ecs@gmail.com ${ }^{3}$ Mestra em Engenharia Florestal - Universidade Federal de Santa Maria. E-mail: roberta.fantinel@bol.com.br

${ }^{2}$ Mestre em Engenharia Ambiental - Universidade Federal de Santa Maria.E-mail: tiagofeldkircher@yahoo.com ${ }^{4}$ Professor Doutor - Universidade Federal do Pampa.E-mail: rafaelcabralcruz@gmail.com
\end{abstract}

Artigo recebido em 04/05/2018 e aceito em 25/12/2019

\begin{abstract}
RESUMO
Este trabalho tem por objetivo avaliar e identificar a fragilidade da cobertura da terra em relação à mudança do uso do solo nos municípios localizados no Alto Camaquã, RS. Na metodologia foram atribuídos diferentes pesos (notas) para as diferentes variáveis vinculadas aos cenários: físico, antrópico e biótico. Posteriormente foram utilizadas imagens do modelo digital de elevação Shuttle Radar Topography Mission (SRTM) disponibilizadas pela Embrapa e executadas no software ArcGIS para a elaboração dos mapas. Os resultados apresentaram uma fragilidade alta no meio físico, nas áreas com declividade superior a 43\%, alta e média fragilidade no meio antrópico e no meio biótico respectivamente. Espera-se que através dos resultados obtidos, possam ser utilizados em projetos de recuperação e na análise das fragilidades ambientais locais, além de subsidiar políticas públicas adequadas para o planejamento da cobertura do solo da região.
\end{abstract}

Palavras-chave: Geotecnologias; mapeamento socioambiental; modelo conceitual.

\section{ENVIRONMENTAL FRAGILITY VERSUS LAND USE IN ALTO CAMAQŨ̃, RS}

\begin{abstract}
This study aims to evaluate and identify the weakness of the land cover in relation to land use change in the municipalities located in the Alto Camaquã, RS. In the methodology were assigned different weights (notes) for the different variables related to the scenarios: physical, biotic and anthropogenic. Later, images from digital elevation model Shuttle Radar Topography Mission (SRTM) available by Embrapa and implemented in ArcGIS software for the preparation of maps. The results showed a high fragility in the physical environment, in areas with slopes above $43 \%$, high and medium weakness in man-made environment and the biotic respectively. It is hoped that through the results obtained can be used in restoration projects and analysis of local environmental weaknesses, in addition to supporting appropriate public policies for planning the soil cover of the region.
\end{abstract}

Keywords: Geotechnologies, mapping socioenvironmental, conceptual model. 


\section{INTRODUÇÃO}

O estudo da fragilidade ambiental constitui uma das principais ferramentas utilizadas pelos órgãos públicos na elaboração do planejamento territorial e ambiental, permitindo que o mapeamento considere a dinâmica do meio ambiente, combinando as características ambientais com suas restrições (CARMO et al., 2011). Sporl et al. (2001), ressaltam que os mapeamentos das fragilidades ambientais identificam e analisam as áreas em função de seus diferentes níveis de fragilidade, mapeando seus graus e permitindo ações tecnicamente mais adequadas a essas condições.

O modelo de fragilidade ambiental é um modelo espacialmente distribuído, o qual consiste inicialmente na elaboração de mapas básicos e mapas temáticos, que combinados e classificados, relacionando sua potencialidade de gerar ou sofrer impactos, dão origem a mapas de fragilidades ambientais (UNIPAMPA/UFSM/MMA, 2009).

Segundo Assad et al. (1998) os mapas temáticos descrevem a distribuição espacial de uma grandeza geográfica, como por exemplo os mapas de aptidão agrícola de uma determinada região. Estes dados são obtidos a partir de levantamento de campo e inseridos no sistema de digitalização ou, a partir de classificação de imagens, de forma automatizada.

Para Coelho (2001) uma investigação mais criteriosa deve ser elaborada considerandose cada caso em particular e possibilitando a análise dos dados existentes em uma área específica, tais como a localização, distâncias, características morfológicas, uso e cobertura da terra, entre outros.

Cabe ainda ressaltar, que estudo sobre o meio físico, biótico e meio antrópico, se faz necessário, pois os mesmos influenciam na alteração do uso e cobertura da terra, conduzindo para problemas, de cunho ambiental, social e econômico, que podem proporcionar graves consequências socioambientais para um território que está a "margem do desenvolvimento". Partindo deste pressuposto, o território do Alto Camaquã, é um espaço geográfico construído socialmente ao longo de 150 anos de ocupação (BORBA e TRINDADE, 2010), é onde se manifestam as relações de sociedade - natureza no formato de território - rede, além, de aspectos culturais e funcionais (NESCK, 2009).

Partindo desta problemática, o objetivo do trabalho foi avaliar e identificar a fragilidade ambiental da cobertura da terra em relação à mudança do uso do solo nos municípios localizados no território do Alto Camaquã e Médio Superior da Bacia Hidrográfica do Rio Camaquã. 


\section{MATERIAIS E MÉTODOS}

\section{Caracterização da área do estudo}

A área de estudo compreende os municípios que fazem parte território do Alto Camaquã (Bagé, Caçapava do Sul, Dom Pedrito, Hulha Negra, Lavras do Sul, Pinheiro Machado, Piratini e Santana da Boa Vista) no Estado do Rio Grande do Sul, localizada entre as coordenadas $30^{\circ} 08^{\prime}$ e $31^{\circ} 53^{\prime}$ de latitude Sul e $52^{\circ} 51^{\prime}$ e $55^{\circ} 09^{\prime}$ de longitude Oeste (Figura 1).

Figura 1 - Mapa da localização dos municípios que compõem o Alto Camaquã - RS.

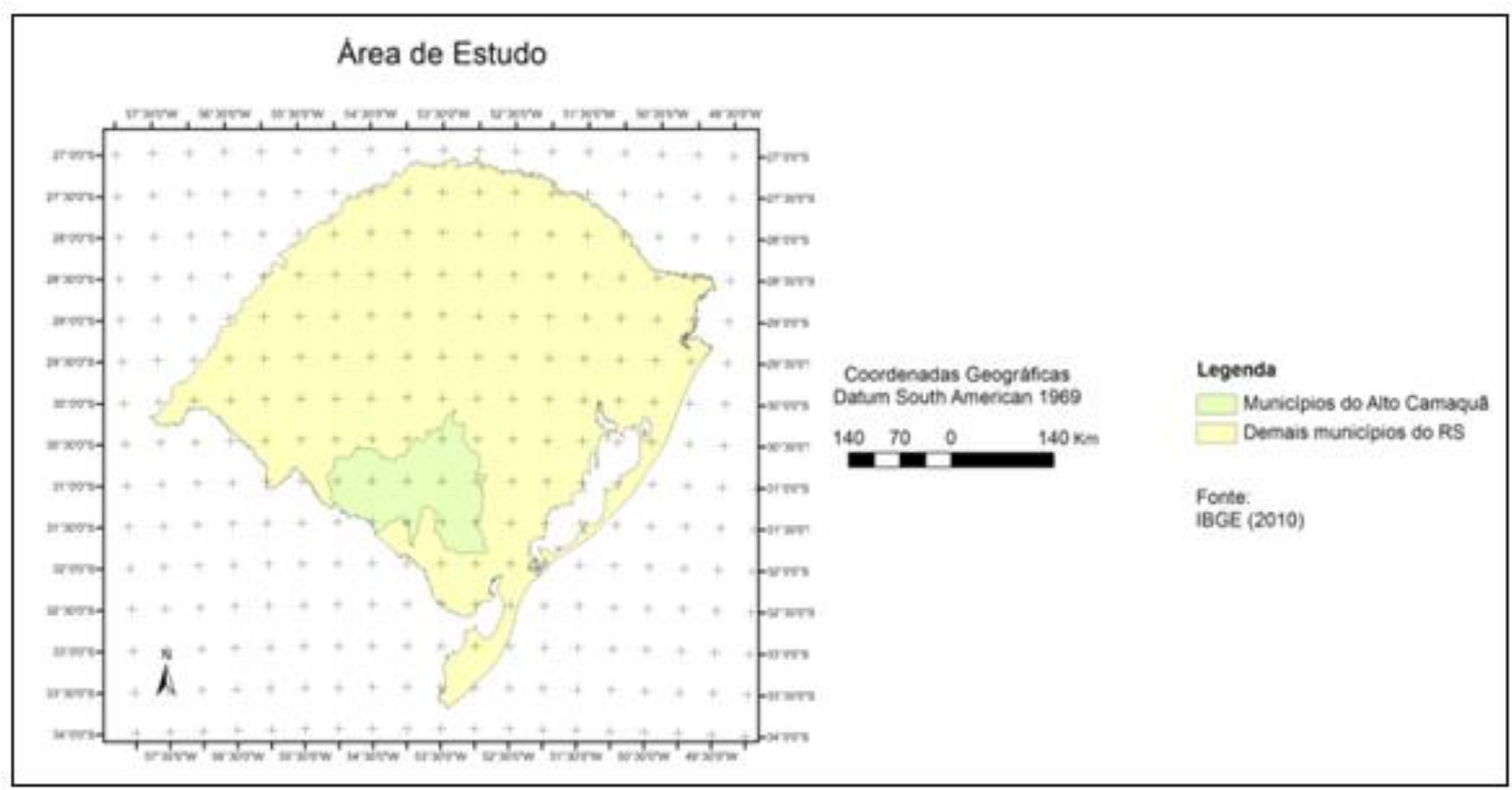

A área pertence à região da Serra do Sudoeste do Rio Grande do Sul, localizada na região da bacia hidrográfica do Alto Camaquã, sub-bacia da bacia hidrográfica do rio Camaquã.

A sub-bacia do Alto Camaquã, por estar inserida no Bioma Pampa, revela uma combinação particular de elementos abióticos com uma diversidade biológica muito presente, sendo a associação destas características responsável por uma beleza paisagística inusitada (NESKE, 2009). Deste modo as particularidades da paisagem encontrada no Alto Camaquã revelam a existência de um grande patrimônio natural e histórico-cultural a ser preservado (FIQUEIRÓ et al., 2011). 


\section{Elaboração dos mapas}

Para analisar o ambiente como um todo, realizou-se uma revisão de literatura sobre o tema, visando à escolha das variáveis que seriam utilizadas nas análises. Após análise identificou-se as seguintes variáveis de ambiente: Físico, Biótico e Antrópico. Para as variáveis do ambiente físico consideraram-se os mapas de declividade e de resistência de solo do Estado do Rio Grande do Sul (FEPAM, 2001), o qual demonstra as características da capacidade da mudança potencial que o ambiente físico tem em relação à cobertura da terra.

Referente ao ambiente biótico foi utilizado o mapa de vegetação remanescente, disponível pelo Ministério do Meio Ambiente (MMA, 2006), que buscou sintetizar a importância da vegetação frente à mudança da cobertura da terra. Por fim, para o ambiente antrópico foi utilizado o mapa de uso do solo do RS, disponibilizado pelo Instituto Brasileiro de Geografia e Estatística (IBGE, 2010).

A realização dos mapas de fragilidade deu-se primeiramente pela integração das informações por meio dos processos de álgebra de mapas, que consiste na sobreposição de layers de diferentes informações referentes a variáveis bióticas, antrópicas e físicas da região. O método de álgebra de mapas, segundo Barbosa et al. (1998) é a linguagem especializada para realizar operações que tem tanto um sentido matemático quanto cartográfico e espacial.

Foram considerados três cenários, denominados Fragilidade Física, Fragilidade Antrópica e Fragilidade Biótica, uma vez os cenários foram elaborados a partir de distintas distribuições de pesos para cada meio. Os pesos atribuídos devem ser de acordo com a opinião dos pesquisadores do trabalho, bem como a opinião dos técnicos especializados no tema em discussão.

Deste modo, foi utilizada a superposição de mapas, através da atribuição de pesos para cada variável, sendo que estes devem totalizar 100\% (CARDOSO et al., 2015) em cada avaliação da fragilidade, para gerar a estimativa da fragilidade sob a forma de um novo mapa, conforme apresenta a Tabela 1. 
Tabela 1 - Valores dos pesos atribuídos para os mapas de fragilidade de cada cenário.

\begin{tabular}{c|c|c}
\hline Cenários & Variáveis & Pesos (\%) \\
\hline \multirow{4}{*}{ Fragilidade física } & Meio físico & 50 \\
\cline { 2 - 3 } & Meio antrópico & 25 \\
\cline { 2 - 3 } & Meio biótico & 25 \\
\hline \multirow{4}{*}{ Fragilidade antrópica } & Meio físico & 25 \\
\cline { 2 - 3 } & Meio antrópico & 50 \\
\cline { 2 - 3 } & Meio biótico & 25 \\
\hline \multirow{3}{*}{ Fragilidade biótica } & Meio físico & 25 \\
\cline { 2 - 3 } & Meio antrópico & 25 \\
\cline { 2 - 3 } & Meio biótico & 50 \\
\hline
\end{tabular}

Para cada variável foram atribuídas notas, que variam de 0 a 255 (número de cores disponíveis no programa utilizado), mesma metodologia adota do projeto FRAG-RIO (MMA, 2009), tornando possível elaborar os mapas de fragilidade. Valores próximos de 255 indicam áreas mais suscetíveis à interferência na modificação da cobertura da terra, frente a mudança de uso do solo dessa região.

\section{Variável declividade}

As informações referentes à declividade da área de estudo foram obtivas por meio do processamento das imagens do modelo digital de elevação Shuttle Radar Topography Mission (SRTM), (MIRANDA, 2005), disponibilizado pelo site da Embrapa e executado no software ArcGis. Para a variável da declividade, as notas atribuídas (Tabela 2) seguem o aumento da declividade, logo, quanto maior a declividade da área do estudo, maior a nota. 
Tabela 2 - Notas atribuídas para cada classe de declividade.

\begin{tabular}{c|c}
\hline Classes Declividade (\%) & Nota \\
\hline$>43,42$ & 255 \\
\hline $33,38-43,42$ & 205 \\
\hline $23,98-33,38$ & 154 \\
\hline $14,58-23,98$ & 102 \\
\hline $5,18-14,58$ & 52 \\
\hline $0-5,18$ & 1 \\
\hline
\end{tabular}

Variável resistência dos solos

O mapa de resistência do solo utilizado apresenta as seguintes variáveis: profundidade, textura, erodibilidade e aptidão agrícola. Conforme o relatório da Fepam (2001) as notas foram atribuídas para os fatores de solo/terreno quanto à resistência aos impactos ambientais, sendo estas qualificadas em quatro classes: Alta; Média; Baixa e Muito Baixa (Tabela 3). Desta forma, considerou-se que as regiões com alta resistência possuem baixa fragilidade, enquanto as regiões com baixa ou muito baixas resistência possuem alta fragilidade.

Tabela 3 - Notas atribuídas para cada classe de resistência de solo.

\begin{tabular}{c|c}
\hline Classes Resistência & Nota \\
\hline Muito baixa & 255 \\
\hline Baixa & 171 \\
\hline Média & 86 \\
\hline Alta & 1 \\
\hline
\end{tabular}

Os solos da região em sua maioria são rasos e pedregosos, apresentam afloramentos de rochas em áreas de relevo ondulado, sendo vulneráveis à erosão e atribuindo grandes restrições ao uso agrícola (NESKE, 2009).

Os solos predominantes na área do estudo são classificados como: argissolos vermelhoamarelos distróficos e neossolo litólico eutróficos. O solo argissolos vermelho-amarelos distróficos é caracterizado por ser profundo e bem drenado ocorre em relevos suaves ondulados e ondulados e podem ser usados com culturas anuais e campo nativo (STRECK et al., 2008). 
Quanto ao neossolo litólico eutróficos, este apresenta profundidade variada, com formações muito recentes e restrições ao uso agrícola, alta suscetibilidade à erosão hídrica e baixa capacidade de infiltração (STRECK et al., 2008).

\section{Variável uso do solo}

Para o mapeamento da cobertura do solo dos municípios do Alto Camaquã foram estabelecidas as seguintes classes: silvicultura, cultivos temporários, uso em áreas campestres, granífera/cerealíferas, pecuária e área urbana, (Tabela 4).

Tabela 4 - Notas para classes de uso e ocupação do solo.

\begin{tabular}{c|c}
\hline Classes do uso e ocupação & Nota \\
\hline Silvicultura & 255 \\
\hline Cultivos temporários & 171 \\
\hline Uso em área campestre & 171 \\
\hline Granífera e cerealíferas & 171 \\
\hline Agropecuária & 86 \\
\hline Área urbana & 1 \\
\hline
\end{tabular}

Variável vegetação remanescente

A vegetação do Alto Camaquã é bastante heterogênea, classificada como zona de transição ecológica (WEBER, 2006), apresentando mosaicos de florestas e campos naturais. Ainda segundo Overbeck et al. (2009), a vegetação predominante pode ser caracterizada como mosaicos de campo e floresta, sendo as florestas mais desenvolvidas junto às faixas ciliares de rios e arroios. Os campos predominam e podem se apresentar em duas categorias, os campos limpos, sem componentes lenhosos (estrato baixo e contínuo de gramíneas e herbáceas) e campos sujos, campos com arbustos e subarbustos (BOLDRINI et al., 1997; OVERBECK et al., 2009).

Baseado na classificação realizada com a vegetação local (MMA, 2014), foi atribuído valores para cada classe (Tabela 5). 
Tabela 5 - Notas para classes da vegetação remanescente.

\begin{tabular}{c|c}
\hline Vegetação remanescente & Nota \\
\hline Estepe arborizada & 255 \\
\hline Estepe gramíneo-lenhosa & 171 \\
\hline Floresta decidual e semi-decidual & 171 \\
\hline Savana estépica arborizada/ gramíneo-lenhosa & 171 \\
\hline Florestamento e reflorestamento & 191 \\
\hline Agricultura com cultivos cíclicos & 127 \\
\hline Áreas antrópicas & 1 \\
\hline
\end{tabular}

\section{RESULTADOS E DISCUSSÃO}

O meio físico foi determinado a partir das variáveis de declividade e de resistência do solo. A classificação de solos, do ponto de vista do planejamento territorial, conforme destaca a Empresa Brasileira de Pesquisa Agropecuária (EMPRAPA, 2006), desempenha um importante papel na segmentação de paisagens, identificando áreas de maior potencial para fins de utilização, ocupação e áreas impróprias, contribuindo desta forma para a preservação ambiental e uso adequado de ecossistemas.

Neste contexto, os solos estão tipificados em função da sua fragilidade frentes às atividades humanas, naturais, aliado às suas características físicasquímicas e aos elementos motores de formação (NASCIMENTO et al., 2016).

A fragilidade física levou em conta o meio físico com maior peso. Na figura 2 observase que a fragilidade se manteve alta nas áreas de declividade superior a $43 \%$, onde predomina o relevo ondulado e fortemente ondulado, nestas áreas as atividades agrícolas, pastoreio e o reflorestamento são restritos. 
Figura 2 - Fragilidade física dos municípios do Alto Camaquã - RS.

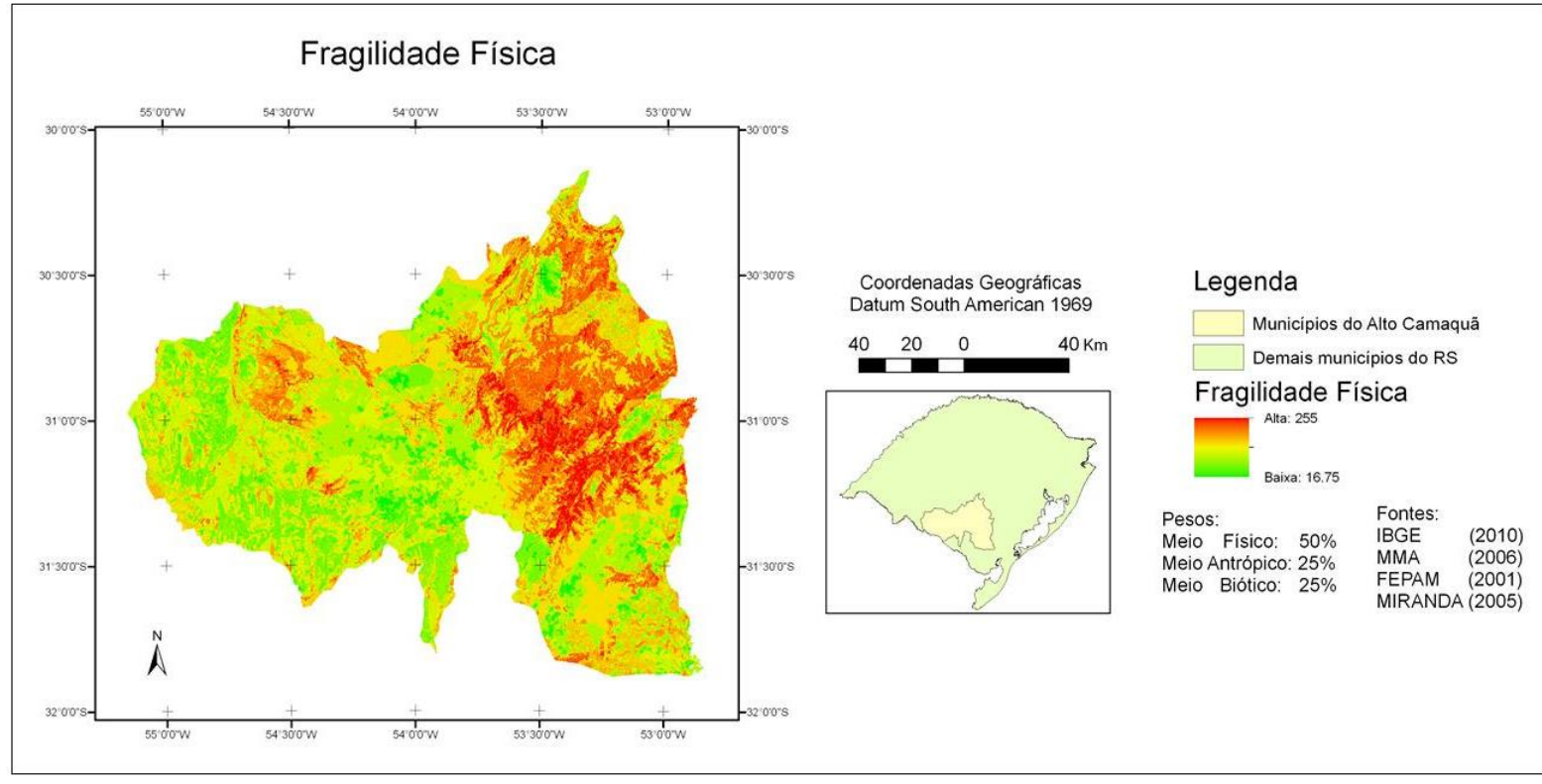

As classes de relevo denominadas como ondulado de acordo com Lepsch et al. (2002), são áreas propicias a erosão e impróprias para culturas anuais, sendo indicadas para culturas perenes, visando proporcionar uma maior proteção ao solo. As áreas de fragilidade baixa configuram regiões de topografia não acidentada destacadas na região centro-oeste, predominando o relevo suave ondulado, sendo possível realizar atividades agrícolas e ações de práticas conservacionistas na área do estudo.

A fragilidade antrópica foi definida considerando o meio antrópico (variável do uso do solo) com maior peso. Nesta classificação a maior parte da fragilidade foi classificada em alta e média (Figura 3). A fragilidade alta (valores próximos de 255) está associada ao uso excessivo da terra, seja por elementos urbanos, a exposição direta do solo, o reflorestamento ou através das atividades agropecuárias. Quanto à fragilidade de valores médios, esta corresponde às áreas de proteção da cobertura vegetal e das práticas conservacionistas que exercem papel fundamental na preservação dos ambientes naturais, favorecendo a infiltração das águas da chuva e reduzindo o risco do escoamento na superfície.

O manejo adequado do campo, direcionado à manutenção da cobertura vegetal e, por conseguinte, à proteção do solo contra a erosão hídrica e eólica, pode impedir ou minimizar os problemas de degradação no futuro (PILLAR et al., 2009). 
Figura 3 - Fragilidade antrópica dos municípios do Alto Camaquã - RS.

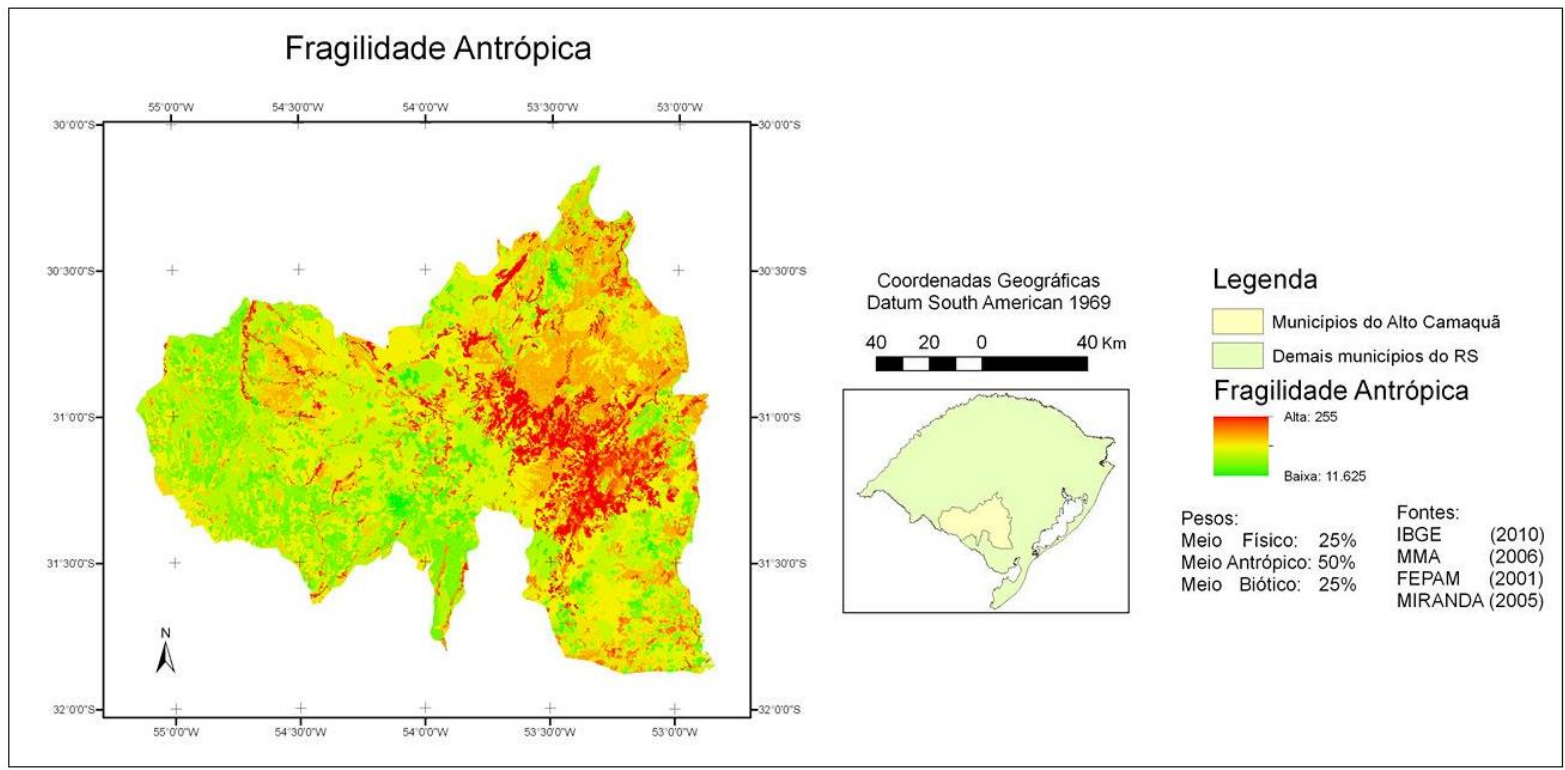

A estrutura e o padrão do uso e cobertura da terra afeta diretamente a vegetação natural, pois uma vez degradado, indiretamente ocasiona a supressão da vegetação nativa, propiciando alteração do meio biótico, acarretando a perda de habitat da sua microfauna, propiciando pragas e diminuição de nichos ecológicos.

Quanto à fragilidade biótica, foi atribuído ao meio biótico (variável vegetação) o peso mais alto, destacando-se a sua fragilidade entre média e alta, sendo destacada na região centro e leste do Alto Camaquã (Figura 4).

Figura 4 - Fragilidade biótica dos municípios do Alto Camaquã - RS.

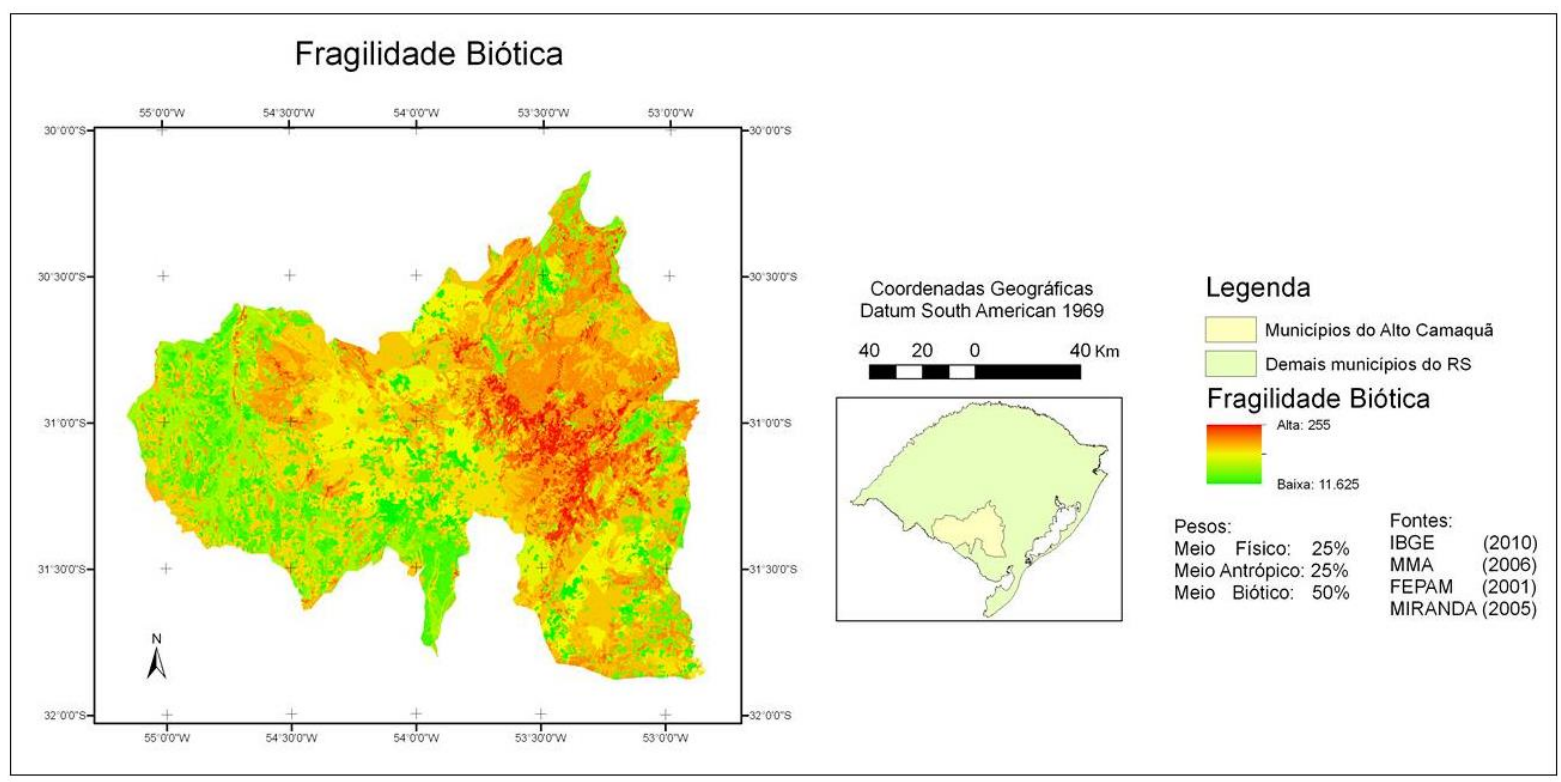


Entre as principais ameaças locais para a biodiversidade está a perda do habitat natural devido à presença da implantação da silvicultura na região de estudo. A perda do habitat natural é causada pela exploração dos recursos florestais, pelas populações humanas (madeira, frutos, lenha, caça) e a exploração da terra para uso humano (agricultura, pecuária e silvicultura) (DEAN,1996). Segundo Sell (2010), a implantação de empreendimentos silviculturais vem afetando, além das características socioculturais da população, também a paisagem natural da região no Bioma Pampa.

Por meio do mapa síntese obtido pode-se observar que as áreas da região centro e leste do Alto Camaquã apresentam os maiores valores de fragilidade, principalmente em função da ocorrência de grandes declives.

Conforme Neske (2009) a porção leste na paisagem do Alto Camaquã apresenta topografia acidentada, com grandes formações rochosas, o que vem a tornar essa área mais frágil. Enquanto que nas áreas da região sul e oeste foram classificados com menor fragilidade (Figura 5).

Figura 5 - Mapa síntese da fragilidade dos municípios do Alto Camaquã - RS.

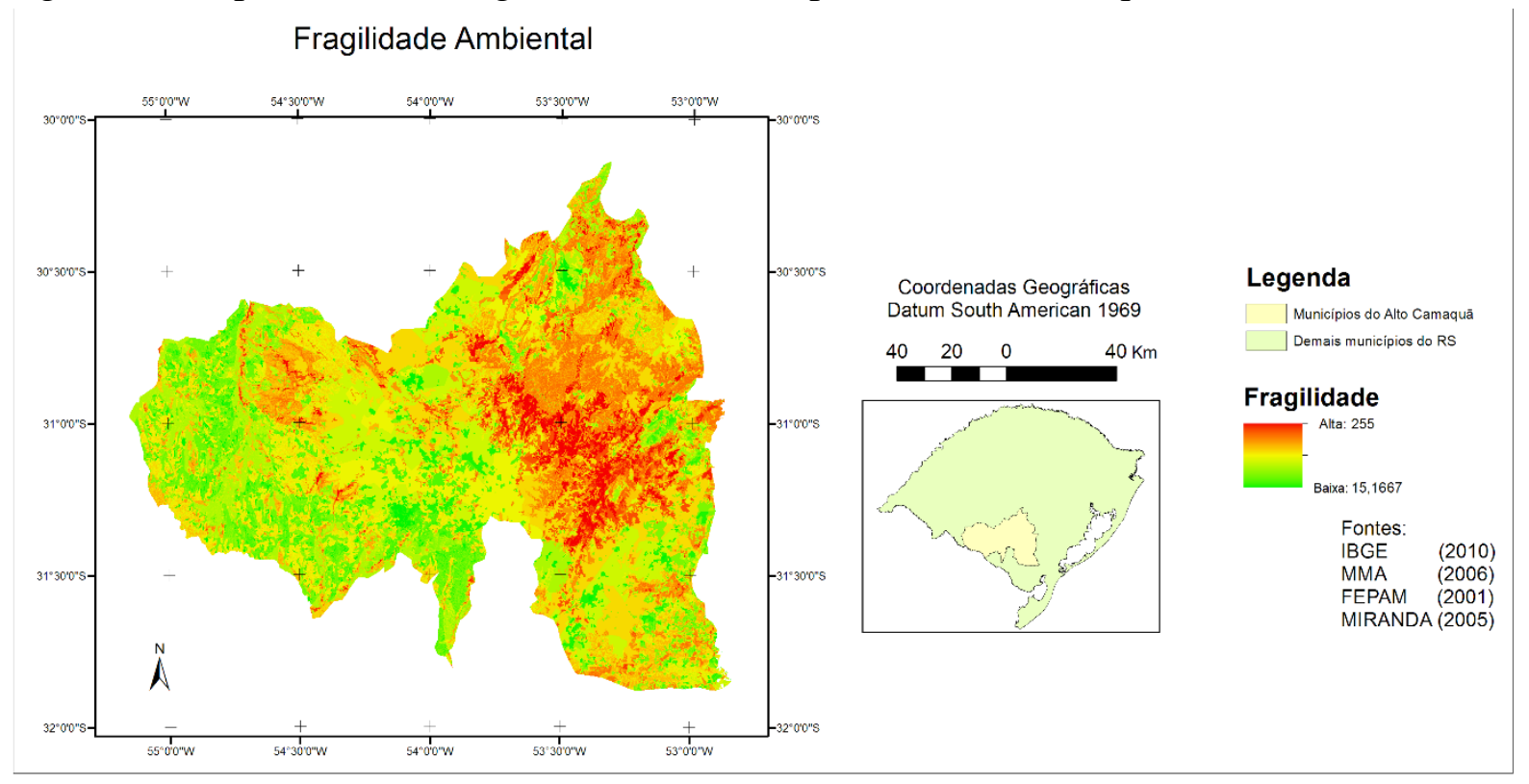




\section{CONCLUSÃO}

A análise dos cenários permitiu constatar que a variável declividade também teve grande influência na determinação de áreas tanto com alta fragilidade na região central da área de estudo, quanto com baixa fragilidade na porção oeste, nos cenários de fragilidade antrópica e biótica, em função do relevo acidentado que a área de estudo apresenta. Quanto ao meio físico, principalmente em função da variável declividade, teve maior influência em todos os cenários analisados no Alto Camaquã.

Os dados obtidos por meio da fragilidade são de grande importância para o entendimento dos processos físicos, bióticos e sociais que ocorrem no território do Alto Camaquã, bem como uma ferramenta que pode auxiliar na tomada de decisões no âmbito do planejamento da cobertura da terra em relação à mudança do uso do solo destes municípios.

\section{REFERÊNCIAS}

ASSAD, E. D.; SANO, E. E. Sistema de informações geográficas - aplicações na agricultura. Embrapa-SPI /Embrapa-CPAC. Brasília: Ed. do Autor, 274p. 1998.

BOLDRINI, I. I.; EGGERS, L. Vegetação campestre do Sul do Brasil: dinâmica de espécies à exclusão do gado. Acta Botânica Brasílica, Brasília, v. 10, n. 1, p. 63-66, 1997.

BORBA, M.; TRINDADE, J. P. P. Desafios para conservação e a valorização da pecuária sustentável. In: PILlAR, V. D.; MÜLLER, S. C.; CASTILHOS, Z.; JAQUES, A.V.A (Org.). Campos Sulinos - conservação e uso sustentável da biodiversidade. Brasília: MMA, (p. 394), 2009.

BARBOSA, C. C.; CAMARA, G.; MEDEIROS, J. S.; CREPANI, E.; NOVO, E.; CORDEIRO, J. P. C. Operadores Zonais em Álgebra de Mapas e Sua Aplicação a Zoneamento EcológicoEconômico. In: SIMPÓSIO BRASILEIRO DE SENSORIAMENTO REMOTO, 9., Santos, 1998. Anais... [S.1.]: INPE, 1998. p. 487-500.

CARDOSO, O. R.; ROCHA, N. S. da.; XAVIER, R.A.;VALDUGA, E. T; DISCONZI, G. S.; RADTKE, L.; CRUZ, R. C. Análise de fragilidade ambiental na bacia do rio Pardo - RS, frente à instalação de pequenas centrais hidrelétricas (PCHs). Revista Brasileira de Recursos Hídricos. v. 20, n. 2, p. 507 - 522, 2015. 
CARMO, J. P. de. A. do; SOUZA, G. F. de; POLIDORO, M.; LOLlO, J. A. de. Análise da fragilidade ambiental em áreas urbanas - O caso do município de Londrina - PR. Anais.. XV Simpósio Brasileiro de Sensoriamento Remoto - SBSR, Curitiba, PR, INPE. p. 0855, 2011.

COELHO, M. C. N. Impactos ambientais em áreas urbanas - teorias, conceitos e métodos de pesquisa. In: GUERRA, A. J. T.; CUNHA, S. B. (Orgs.). Impactos ambientais urbanos no Brasil. Rio de Janeiro: Bertrand Brasil, 2001.

DEAN, W. A ferro e fogo: a história e a devastação da Mata Atlântica brasileira. Companhia das Letras, São Paulo. 1996.

FEPAM. Fundação Estadual de Proteção Ambiental Henrique Luis Roessler. Mapa de Classificação dos solos do Estado do Rio Grande do Sul quanto à resistência a impactos ambientais. Porto Alegre: FEPAM. 13 p. (n.publ.) Relatório final de consultoria elaborado por Nestor Kämpf. Mapa em meio digital. 2001.

IBGE. Projeto Levantamento e Classificação do Uso da Terra - Uso da Terra no Estado do Rio Grande do Sul. Relatório Técnico. Rio de Janeiro: IBGE, 2010. Disponível em: <ftp://geoftp.ibge. gov.br/documentos/recursos_naturais/manuais_tecnicos/ usoterra_rs.pdf>. Acesso em: 10 de fev. 2017.

LEPSCH, I. F. 2002. Formação e conservação dos solos. Oficina de Textos, São Paulo.

MMA. Ministério do Meio Ambiente. Mapa das Áreas Prioritárias para conservação, uso sustentável e repartição de benefícios da biodiversidade brasileira. 2006. Disponível em:<http://www.mma.gov.br/biodiversidade/biodiversidade-brasileira/\%C3\%A1reaspriorit\%C3\%A1rias/item/489>. Acesso em: 8 de março de 2017.

MMA. Ministério do Meio Ambiente. Desenvolvimento Metodológico e Tecnológico para Avaliação Ambiental Integrada Aplicada ao Processo de Análise de Viabilidade de 
Hidrelétricas. FRAG-RIO. [Brasília]: MMA, 2011. Relatório Etapa 2. Convênio FINEP/UFSM/ UNIPAMPA. Processo n. 520204/2008-5. Junho de 2011.

MIRANDA, E. E. de. Brasil em Relevo. Campinas: Embrapa Monitoramento por Satélite, 2005. Disponível em: <http://www.relevobr.cnpm.embrapa.br> Acesso em: 10 de março. 2017.

NASCIMENTO, N. S.; VIEIRA, E. M.; GONÇALVES, J. A. C.; CUNHA, G. de. P. Q. Estudo da vulnerabilidade ambiental em uma micro bacia hidrográfica empregando hierarquia nominal e operador local. Revista Brasileira de Geografia Física, v. 09 n. 03, p. 897-916, 2016.

NESKE, M. Z. 2009. 207 p. Estilos de agricultura e dinâmicas locais de desenvolvimento Rural: o caso da pecuária familiar no território Alto Camaquã no Rio Grande do Sul. Dissertação (Mestrado em Desenvolvimento Rural) Universidade Federal do Rio Grande do Sul, Porto Alegre, Rio Grande do Sul, Brasil. 2009.

OVERBECK, G. E.; MULHER, S. C., FIDELIS, A.; PFADENHAUER, J.; PILLAR, V. P. Os campos sulinos: um bioma negligenciado. In: PILLAR, V. D.; MÜLLER, S. C.; CASTILHOS, Z.; JAQUES, A.V.A (Org.). Campos Sulinos - conservação e uso sustentável da biodiversidade. Brasília: MMA, (p. 26-41), 2009.

PILlAR, V. de. P.; MÜlleR, S. C.; CASTILHOS, Z. M. de. S.; JACQUES, A. V. A. Campos Sulinos: conservação e uso sustentável da biodiversidade. Editores. - Brasília: MMA, p. 403. 2009.

SPORL, C. Análise da Fragilidade Ambiental Relevo-Solo com Aplicação de três Modelos Alternativos nas Altas Bacias do Rio Jaguari-Mirim, Ribeirão do Quartel e Ribeirão da Prata. 2001. (Dissertação de Mestrado) FFLCH - Departamento de Geografia, USP Universidade de São Paulo, São Paulo.

SELL, J. C.; FIGUEIRÓ, A. S. Modelos de (des)envolvimento em disputa na Sub-Bacia do Alto Camaquã - RS. Geografia: Ensino \& Pesquisa, v. 14, n. 1, p. 32- 42, 2010. 
STRECK, E. V.; KAMPF, N; DALMOLIN, R. S. D.; KLAMT, E.; NASCIMENTO, P. C; SCHNEIDER, P. Solos do Rio Grande do Sul. 2. ed. Porto Alegre: EMATER/ASCARRS, 2008. 222p.

UNIPAMPA/UFSM/MMA. Desenvolvimento Metodológico e Tecnológico para Avaliação Ambiental Integrada Aplicada ao Processo de Análise da Viabilidade de Hidrelétricas Projeto FRAG-RIO. Relatório Técnico da Etapa I. Santa Maria: FATEC/UNIPAMPA/UFSM. 307 p. 2009.

WEBER, E. J. H. Base cartográfica digital do Rio Grande do Sul escala 1:250.000. Porto Alegre. 2006. 